\title{
Effects of dietary polychlorinated biphenyls on cholesterol catabolism in rats
}

\author{
BY SATOSHI NAGAOKA*, HITOSHI MIYAZAKI, YORITAKA AOYAMA \\ AND AKIRA YOSHIDA $\dagger$ \\ Laboratory of Nutritional Biochemistry, Department of Agricultural Chemistry, Nagoya University, \\ Nagoya 464, Japan
}

(Received 29 June 1989 - Accepted 4 January 1990)

\begin{abstract}
Dietary polychlorinated biphenyls (PCBs) caused hypercholesterolaemia in rats. The concentration and output of biliary cholesterol was significantly lower than that of the control group. Biliary output of total bile acids was significantly decreased in rats given the PCB-supplemented diet. Faecal excretion of total steroids (sum of neutral steroids and acidic steroids) was not significantly changed in rats given the PCBsupplemented diet. The present results indicate that dietary PCBs cause hypercholesterolaemia without modifying the faecal total steroids excretion. These results suggest that PCBs produce hypercholesterolaemia accompanied by changes in biliary or faecal excretion of bile acids and neutral steroids in addition to an increase in hepatic cholesterol synthesis.
\end{abstract}

Bile acids: Cholesterol: Polychlorinated biphenyls: Rat

The metabolism of cholesterol is subject to complex control and is altered by a number of environmental, hormonal and dietary factors. Dietary hypercholesterolaemia in animal experiments is usually produced by giving a high-cholesterol diet (Frantz et al. 1954; Harry et al. 1973; O'Brien \& Reiser, 1982).

Recently we reported that the administration of polychlorinated biphenyls (PCBs), 1,1,1trichloro-2,2-bis( $p$-chlorophenyl)ethane (DDT), butylated hydroxyanisole (BHA) and other xenobiotics caused a fatty liver and hypercholesterolaemia in rats (Kato \& Yoshida, 1981; Nagaoka et al. $1986 a, b$ ). When diets supplemented with PCBs or other xenobiotics were given, the incorporation of ${ }^{3} \mathrm{H}_{2} \mathrm{O}$ into liver cholesterol was stimulated together with an increase in the activity of liver 3-hydroxy-3-methylglutaryl coenzyme A (HMG-CoA) reductase (EC 1.1.1.34), suggesting a stimulation of cholesterol synthesis (Kato \& Yoshida, 1980; Nagaoka et al. 1986 b). The mechanism by which dietary PCBs induce hypercholesterolaemia in rats is not well understood. To our knowledge, no one has studied the effect of PCBs on cholesterol catabolism, such as faecal or biliary excretion of steroids.

Dietary cholesterol and bile acids have been reported to affect cholesterol synthesis and degradation to bile acids. The composition and amount of bile acids passing through the liver influence cholesterol and bile acid metabolism (Uchida et al. 1978; Tanaka et al. 1984). Uchida et al. (1978) investigated the age-related changes in serum and liver cholesterol, biliary secretion of steroids and faecal steroid excretion. They postulated that the decrease of chenodeoxycholic acid caused hypercholesterolaemia in aged rats, based on biliary bile acid composition. Other conditions, such as ascorbic acid deficiency (Ginter et al. 1971; Holloway \& Rivers, 1981) or hypothyroidism (Takeuchi et al. 1975; Abrams \& Grundy, 1981) associated with changes in cholesterol catabolism, may be a more important factor

* Present address: Department of Food Science, Faculty of Agriculture, Gifu University, Gifu 501-11, Japan.

$\dagger$ For reprints. 
Table 1. Composition of the diets $(\mathrm{g} / \mathrm{kg})$

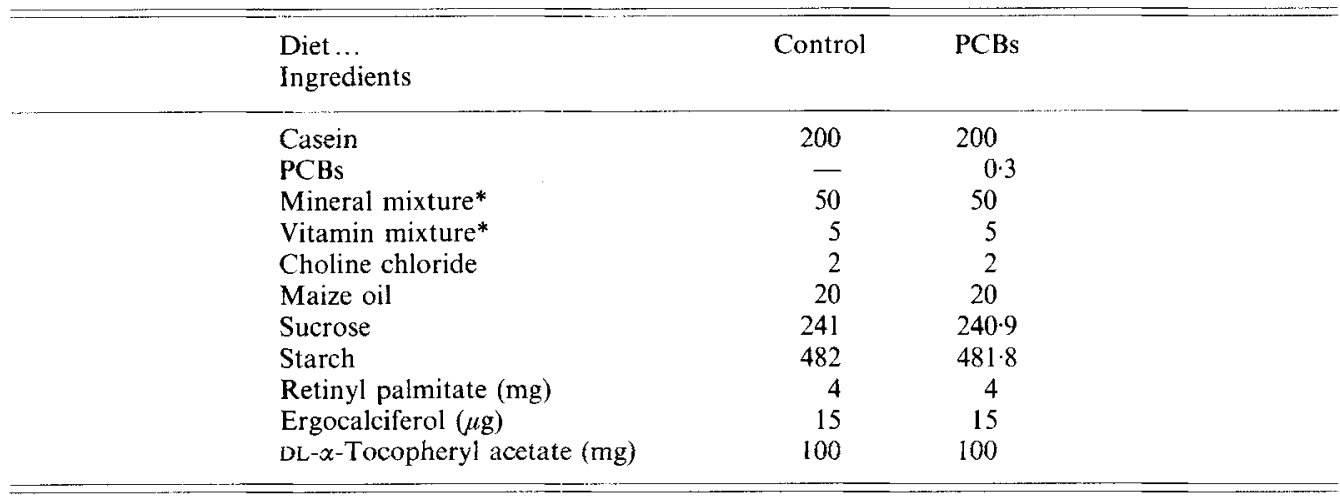

PCBs, polychlorinated biphenyls.

* Composition as described by Harper (1959).

than cholesterol synthesis to the development of hypercholesterolaemia. These findings demonstrate that cholesterol catabolism as well as its synthesis is an important factor in understanding the mechanism of the control of plasma cholesterol level. We postulate that PCB-induced hypercholesterolaemia may also bring about changes in cholesterol catabolism, bile composition and faecal steroids excretion. Therefore, in the present study we investigated the effects of PCBs on these variables.

\section{MATERIALS AND METHODS}

Animals and diets

The animals used in the present study were male Wistar rats weighing about $90 \mathrm{~g}$ in Expt 1 , and about $250 \mathrm{~g}$ in Expt 2 . Room temperature was kept at $22 \pm 2^{\circ}$ with a $12 \mathrm{~h}$ cycle of light (08.00-20.00 hours) and dark.

Expt 1. Rats were fed on a commercial stock diet (CE-2; Japan CLEA Co. Ltd, Tokyo) for $3 \mathrm{~d}$ to allow them to adapt to the new environment. They were offered a diet adequate in casein $(200 \mathrm{~g} / \mathrm{kg})$ for $2 \mathrm{~d}$ before receiving the test diet shown in Table 1 . All rats were individually housed and provided with feed and water ad lib. A mixture of PCBs (Aroclor 1248; Mitsubishi Monsant Co. Ltd, Tokyo) was added to the diets $(0.3 \mathrm{~g} / \mathrm{kg})$. Changes in the dietary level of PCB was compensated for by adjusting the amounts of carbohydrates, composed of one part sucrose and two parts gelatinized maize starch. Fat-free diets were prepared by replacing maize oil with carbohydrates. The rats were divided into two groups of six rats each. On days 10-12, faeces were collected and used for determination of faecal steroids. For $24 \mathrm{~h}$ before killing, the animals were given fat-free diets. At the end of the experimental period ( 2 weeks), rats were anaesthetized with diethyl ether and killed at 09.00 hours within a short period. Blood was collected by cardiac puncture for analysis of serum lipids. After killing the rats, livers were immediately excised for assay of cholesterol $7 \alpha-$ hydroxylase (EC 1.14.13.17) activity.

Expt 2. Rats were fed on a commercial stock diet (CE-2, Japan CLEA Co. Ltd) for 3 $\mathrm{d}$ to allow them to adapt to the new environment. They were offered a diet adequate in casein $(200 \mathrm{~g} / \mathrm{kg})$ for $2 \mathrm{~d}$ before receiving the test diet shown in Table 1 . All rats were individually housed and provided with feed and water $a d$ lib. The rats were divided into two groups of eleven rats each. On the last day of the experimental period ( 2 weeks), the diet was removed from individual cages at 09.00 hours. Rats were anaesthetized with sodium 
pentobarbital ( $50 \mathrm{mg} / \mathrm{kg}$ body-weight intraperitoneally) between 13.00 and 15.00 hours, and the bile duct was cannulated with PE-10 polyethylene tubing for the analysis of biliary steroids. The bile was continuously collected in a tube for $1 \mathrm{~h}$. Bile duct cannulation and bile collection were done in the anaesthetized state according to the method of Uchida et al. (1978). After the termination of bile collection, the rats were killed. Blood was collected by cardiac puncture for the analysis of serum cholesterol.

\section{Analytical procedures}

Serum and liver lipid analyses. Serum and liver cholesterol concentrations were measured according to the method of Pearson et al. (1953). High-density-lipoprotein (HDL)cholesterol was separated by the heparin-manganese method described by Ishikawa et al. (1978). Serum triacylglycerol value was estimated by the method of Wahlefield (1974). Serum phospholipid was assayed with a commercially available kit (Phospholipid-Test; Wako Pure Chemical Industries Ltd) by the method described by Zilversmit \& Davis (1950). Liver lipids were extracted by the method of Folch et al. (1957). Liver total lipids were determined gravimetrically. Total lipid-phosphorus was determined by the method of Bartlett (1959), and the values were multiplied by 25 to obtain the phospholipid content of liver. Liver triacylglycerol value was calculated from liver total lipids minus liver cholesterol and phospholipids (Quazi et al. 1983).

Biliary and faecal steroids analyses. Biliary bile acid composition was analysed by highperformance liquid chromatography (HPLC; TRI ROTER-V; JASCO), with an immobilized $3 \alpha$-hydroxysteroid dehydrogenase (EC 1.1.1.50) column (Enzymepak-HSD) (Okuyama et al. 1979). Total bile acids in bile were determined enzymically with sodium taurocholate as a standard (Bruusgaard et al. 1977) Faecal acidic steroids were measured according to the method of Bruusgaard et al. (1977) and Malchøw-Møller et al. (1982). Faecal neutral steroids were assayed as trimethyl silyl ether by using $1.5 \%$ OV-17 on GasChrom Q (Shimadzu Co. Ltd) with $5 \alpha$-cholestane as an internal standard (Miettinen et al. 1965).

Preparation of liver microsomes. After killing the rats, livers were immediately excised and were chilled in ice and washed with ice-cold $0.25 \mathrm{M}$-sucrose. Liver microsomes for the assay of cholesterol $7 \alpha$-hydroxylase activity were prepared according to the method described by Van Cantfort et al. (1975). About $1 \mathrm{~g}$ liver was homogenized with $30 \mathrm{~mm}$ nicotinamide and $1 \mathrm{~mm}$-EDTA in a Potter-Elvehjem homogenizer. The homogenate was centrifuged at $9000 \mathrm{~g}$ for $10 \mathrm{~min}$ at $4^{\circ}$ and the supernatant fraction obtained was again centrifuged at $105000 \mathrm{~g}$ for $60 \mathrm{~min}$ at $4^{\circ}$. The pellet was immediately stored at $-70^{\circ}$.

Assay of cholesterol $7 \alpha$-hydroxylase activity. Liver microsomal cholesterol $7 \alpha-$ hydroxylase activity was assayed as described by Van Cantfort et al. (1975). The [7(n)${ }^{3} \mathrm{H}$ ]cholesterol (specific activity $12.54 \times 10^{6}$ disintegrations/min per $\mathrm{nmol}$ ) at a final concentration of $225 \mu \mathrm{M}$, solubilized with Tween $-80(1.5 \mathrm{mg} / \mathrm{ml})$ according to the method of Karaboyas \& Koritz (1965), was used for the assay. The incubation mixture ( $1 \mathrm{ml})$ contained an enzyme preparation equivalent to $20 \mathrm{mg}$ liver, $20 \mathrm{~mm}$-glucose-6-phosphate, 2 mm-NADP, 1 IU glucose-6-phosphate dehydrogenase (EC 1.1.1.49), 100 m m-potassium phosphate buffer ( $\mathrm{pH} \mathrm{7.4),20} \mathrm{mm-cysteamine} \mathrm{and} 4$ mM-magnesium chloride. The assay was started by incubating the tubes in a shaking water-bath at $37^{\circ}$ for $30 \mathrm{~min}$ in the dark. The enzyme reaction was stopped by adding 3 vol. trichloroacetic acid $(200 \mathrm{~g} / 1)$. After centrifugation, the supernatant fractions were distilled. The radioactivity of ${ }^{3} \mathrm{H}_{2} \mathrm{O}$ was counted using a liquid-scintillation system.

\section{Statistical analysis}

The data were statistically evaluated by Student's $t$ test (Snedecor \& Cochran, 1967). 
Table 2. Expt 1. Effects of dietary addition of polychlorinated biphenyls (PCBs) on body-and liver weights, food intake, serum and liver lipids, cholesterol $7 \alpha$-hydroxylase (EC 1.14.13.17) activity and faecal steroid excretion in rats

(Mean values with their standard errors for six rats per group)

\begin{tabular}{|c|c|c|c|c|}
\hline \multirow[t]{2}{*}{ Group... } & \multicolumn{2}{|c|}{ Control } & \multicolumn{2}{|c|}{$\begin{array}{c}\text { PCBs } \\
(0 \cdot 3 \mathrm{~g} / \mathrm{kg})\end{array}$} \\
\hline & Mean & $\mathrm{SE}$ & Mean & SE \\
\hline Food intake, day $6(\mathrm{~g})$ & $14 \cdot 4$ & 0.6 & 15.0 & $1 \cdot 2$ \\
\hline Body-wt gain $(\mathrm{g} / 14 \mathrm{~d})$ & $64 \cdot 2$ & 1.6 & $70 \cdot 8$ & $5 \cdot 6$ \\
\hline Liver wt $(\mathrm{g} / \mathrm{kg}$ body-wt) & $51 \cdot 4$ & 02 & $79 \cdot 2 * * *$ & 0.2 \\
\hline \multicolumn{5}{|l|}{ Serum $(\mathrm{mg} / \mathrm{l})$} \\
\hline Total cholesterol & 943 & 56 & $1800^{* * *}$ & 50 \\
\hline HDL-cholesterol & 588 & 53 & $1029^{* * *}$ & 51 \\
\hline LDL + VLDL-cholesterol & 355 & 28 & $771^{* * *}$ & 37 \\
\hline Triacylglycerol & 1659 & 218 & 1600 & 250 \\
\hline Phospholipids & 2400 & 86 & $3800^{* * *}$ & 80 \\
\hline \multicolumn{5}{|l|}{ Liver (mg/g liver) } \\
\hline Total lipids & $51 \cdot 8$ & 0.5 & $68 \cdot 3 * * *$ & $1 \cdot 3$ \\
\hline Cholesterol & $2 \cdot 0$ & $0 \cdot 1$ & $3 \cdot 3 * * *$ & 0.2 \\
\hline Triacylglycerol & $22 \cdot 3$ & $1 \cdot 0$ & $28 \cdot 0^{* *}$ & 1.5 \\
\hline Phospholipids & $27 \cdot 5$ & 0.6 & $37 \cdot 0^{* * *}$ & 0.5 \\
\hline \multicolumn{5}{|c|}{ Cholesterol $7 \alpha$-hydroxylase activity $\dagger$} \\
\hline$/ \mathrm{mg}$ protein & $1 \cdot 44$ & 0.08 & $0.89^{*}$ & 0.15 \\
\hline /g liver & $33 \cdot 7$ & 1.4 & $22 \cdot 8^{*}$ & $4 \cdot 1$ \\
\hline /liver per $\mathrm{kg}$ body-wt & 1478 & 43 & 1556 & 296 \\
\hline Faecal dry weight $(\mathrm{g} / \mathrm{d})$ & 0.43 & 0.03 & 0.44 & 0.01 \\
\hline \multicolumn{5}{|l|}{ Faecal neutral steroids $(\mu \mathrm{mol} / \mathrm{d})$} \\
\hline Coprostanol & $5 \cdot 27$ & 1.06 & $5 \cdot 29$ & $0 \cdot 40$ \\
\hline Cholesterol & 1.58 & 0.26 & $3.93 * *$ & 0.59 \\
\hline Total & 6.85 & $1 \cdot 26$ & $9 \cdot 22$ & 0.78 \\
\hline Faecal acidic steroids $(u \mathrm{~mol} / \mathrm{d})$ & $2 \cdot 83$ & $0 \cdot 25$ & $0.87^{* * *}$ & 0.28 \\
\hline Faecal total steroids $\$(\mu \mathrm{mol} / \mathrm{d})$ & $9 \cdot 68$ & $1 \cdot 31$ & $10 \cdot 09$ & 0.53 \\
\hline
\end{tabular}

HDL, high-density lipoprotein; LDL, low-density lipoprotein; VLDL, very-low-density lipoprotein.

Mean values were significantly different from those for the control group: ${ }^{*} P<0.05,{ }^{* *} P<0.01,{ }^{* *} P<0.001$. $\dagger$ nmol $7 \alpha$-hydroxycholesterol produced/h.

$\ddagger$ Total steroids $=$ neutral steroids + acidic steroids.

\section{RESULTS \\ Expt 1}

Food intake and growth rate of rats given the PCB-supplemented diet were not different from those of rats given the casein $(200 \mathrm{~g} / \mathrm{kg})$ diet, although hepatomegaly was observed (Table 2). Serum cholesterol level was significantly increased in rats given the PCBsupplemented diet. Serum triacylglycerol value was not significantly altered by PCBfeeding. Serum phospholipids were significantly increased in rats given the PCBsupplemented diet. Serum HDL-cholesterol and low-density-lipoprotein (LDL)-cholesterol + very-low-density-lipoprotein (VLDL)-cholesterol concentrations also increased significantly in rats given the PCB-supplemented diet. Dietary PCBs increased the concentration of triacylglycerol, phospholipids and cholesterol in the liver. Dietary PCBs produced a significant decrease in the cholesterol $7 \alpha$-hydroxylase activity when the values were expressed as activity per $\mathrm{g}$ tissue or per $\mathrm{mg}$ protein, but the activity was not significantly altered by PCBs when the values were expressed as activity per $\mathrm{kg}$ bodyweight. Table 2 shows the faecal excretion of neutral and acidic steroids in rats given the 
Table 3. Expt 2. Effects of dietary addition of polychlorinated biphenyls (PCBs) on bodyand liver weights, food intake, serum cholesterol and biliary steroids in rats

(Mean values with their standard errors for eleven rats per group)

\begin{tabular}{|c|c|c|c|c|}
\hline \multirow[t]{2}{*}{ Group ... } & \multicolumn{2}{|c|}{ Control } & \multicolumn{2}{|c|}{$\begin{array}{c}\text { PCBs } \\
(0 \cdot 3 \mathrm{~g} / \mathrm{kg})\end{array}$} \\
\hline & Mean & SE & Mean & SE \\
\hline Food intake, day $6(\mathrm{~g})$ & $15 \cdot 7$ & $0 \cdot 4$ & $14 \cdot 0$ & $0-4$ \\
\hline Body-wt gain $(\mathrm{g} / 14 \mathrm{~d})$ & $17 \cdot 3$ & $1 \cdot 1$ & $16 \cdot 3$ & $1 \cdot 2$ \\
\hline Liver wt $(\mathrm{g} / \mathrm{kg}$ body-wt) & $34 \cdot 6$ & $0 \cdot 6$ & $46 \cdot 7^{* * *}$ & $0 \cdot 9$ \\
\hline Serum cholesterol $(\mathrm{mg} / 1)$ & 1071 & 18 & $1600^{* * *}$ & 44 \\
\hline Bile flow $(\mu \mathrm{l} / \mathrm{h}$. & 570 & 30 & $800^{* * *}$ & 50 \\
\hline \multicolumn{5}{|c|}{ Biliary output ( $\mu \mathrm{mol} / \mathrm{kg}$ body-wt per $\mathrm{h})$} \\
\hline Cholesterol & 0.53 & 0.04 & $0 \cdot 30^{* * *}$ & 0.02 \\
\hline Bile acids & $39 \cdot 1$ & $1 \cdot 9$ & $28 \cdot 5^{*}$ & $1 \cdot 2$ \\
\hline $\mathrm{GCA} \dagger$ & 634 & 91 & $460^{* *}$ & 33 \\
\hline TCA & 22020 & 2720 & $14875^{* * *}$ & 996 \\
\hline GCDCA & 225 & 35 & $113^{* * *}$ & 8 \\
\hline TCDCA & 1398 & 116 & 1450 & 70 \\
\hline GDCA & 174 & 25 & $102^{* * *}$ & 8 \\
\hline TDCA & 2737 & 473 & $822^{* * *}$ & 79 \\
\hline GCA/TCA & $0 \cdot 029$ & 0.008 & 0.031 & 0.004 \\
\hline GCDCA/TCDCA & $0 \cdot 161$ & 0.014 & $0.078^{* * *}$ & * 0.005 \\
\hline GDCA/TDCA & 0.064 & 0.007 & $0 \cdot 124^{* *}$ & 0.015 \\
\hline
\end{tabular}

GCA, glycocholic acid; TCA, taurocholic acid; GCDCA, glycochenodeoxycholic acid; TCDCA, taurochenodeoxycholic acid; GDCA, glycodeoxycholic acid; TDCA, taurodeoxycholic acid.

Mean values were significantly different from those for the control group: ${ }^{*} P<0.05,{ }^{* *} P<0 \cdot 01,{ }^{* * *} P<0.001$.

$\dagger \mathrm{nmol} / \mathrm{kg}$ body-wt per $\mathrm{h}$.

PCB-supplemented diet. The output of acidic steroids in the faeces was significantly decreased in rats given the PCB-supplemented diet. On the otherhand, PCB feeding caused an increase in faecal excretion of neutral steroids, but this was not statistically significant. Faecal excretion of coprostanol was not significantly altered by PCBs, but there was a significant increase in faecal excretion of cholesterol. Faecal excretion of total steroids (neutral steroids + acidic steroids) was not significantly altered in rats given the PCBsupplemented diet (Table 2).

\section{Expt 2}

As shown in Table 3, PCBs caused a significant increase in the rate of bile flow. The output of biliary cholesterol was significantly decreased in rats given the PCB-supplemented diet. The concentration and output of biliary bile acids were significantly decreased in rats given the PCB-supplemented diet. The output of biliary taurochenodeoxycholic acid was not significantly altered by PCB-feeding. The output of biliary glycocholic acid, taurocholic acid, glycochenodeoxycholic acid, glycodeoxycholic acid and taurodeoxycholic acid were significantly decreased in rats given the PCB-supplemented diet (Table 3). The glycine: taurine conjugation ratio of cholic acid was not significantly altered by PCB-feeding, while that of deoxycholic acid or chenodeoxycholic acid was significantly changed.

\section{DISCUSSION}

The present experiments were designed to study the changes in cholesterol catabolism in rats given a PCB-supplemented diet. Cholesterol $7 \alpha$-hydroxylase catalyses the first and rate-limiting step in the conversion of cholesterol to bile acids in the liver. Dietary PCBs 
produced a significant decrease in the cholesterol $7 \alpha$-hydroxylase activity when expressed per g tissue or per mg protein. Appleton et al. (1981) and Waxman (1986) indicated that DDT or other xenobiotics caused a suppression of cholesterol $7 \alpha$-hydroxylase activity when expressed per mg protein in rats. These observations are similar to our present findings. However, cholesterol $7 \alpha$-hydroxylase activity was not significantly altered by PCB-feeding when values were expressed as activity per $\mathrm{kg}$ body-weight. One might expect that total activity expressed per $\mathrm{kg}$ body-weight would be the most significant. The present results indicate that the faecal excretion of bile acids is not always reflected by changes in cholesterol $7 \alpha$-hydroxylase activity. Thus, we speculate that the observed decrease in faecal bile acid excretion may result from changes in cholesterol reabsorption, or concentrations of substrate in the tissue for cholesterol $7 \alpha$-hydroxylase, or other factors. It is not clear at the moment which method of expressing activity is appropriate in relation to the physiological significance of bile acid excretion.

In the liver, bile acids are synthesized from cholesterol and conjugated with glycine or taurine. A large number of methods have been described for the quantitative determination of the various bile acids (Bruusgaard et al. 1977; Uchida et al. 1978; Okuyama et al. 1979). Okuyama et al. (1979) reported that the method using HPLC in combination with immobilized $3 \alpha$-hydroxysteroid dehydrogenase ( $3 \alpha$-HSD) enzymic detection offered selectivity for $3 \alpha$-hydroxysteroids in man. However, only limited information is available concerning the glycine:taurine conjugation ratio of biliary bile acids in rats. The present findings indicate that the method using HPLC in combination with immobilized $3 \alpha-\mathrm{HSD}$ enzymic determination can be used for biliary bile acids in rats.

It is known that the glycine:taurine conjugation ratio of biliary bile acids is changed under some conditions of dietary treatment or disease; for example, cholestyramine treatment (Heaton et al. 1971) or gastrointestinal diseases (Abaurre et al. 1969). Dietary cholestyramine increased the glycine; taurine conjugation ratio of bile acids (Heaton et al. 1971). Dietary PCBs produced changes in the glycine; taurine conjugation ratios of biliary bile acids. We can speculate that these changes in biliary bile acids may result from the alterations in bile acid synthesis, its reabsorption or intestinal flora, as shown in other studies (Heaton et al. 1971; Abaurre et al. 1969). A specific mechanism for these changes in biliary bile acids in the present studies is unclear.

In the present study, bile flow was increased in rats given a PCB-supplemented diet. Bile flow was also elevated in rats given diets supplemented with DDT (Bastomsky, 1974), phenobarbital (Klassen, 1971) or butylated hydroxytoluene (BHT) (Choe et al. 1984). Choe et al. (1984) suggested that the increased bile flow was due to an increase in bile production from the canal rather than a change in net secretion from the duct or reabsorption of fluid. In the latter case, it appears that the increase in bile flow produced by BHT is due to the osmotic choleresis related to the secretion of BHT and its metabolites into bile (Choe et al. 1984). Yoshimura et al. (1974) reported that dietary PCBs caused an increase in the secretion of PCBs and their metabolites into bile. Phenobarbital is frequently used to investigate the role of biliary excretion in the metabolism of xenobiotics, since phenobarbital induces mixed function oxidase activities which catalyse the metabolism of most foreign compounds (Klassen \& Watkins, 1984). In addition to inducing the mixed function oxidases, phenobarbital, BHT and DDT (Klassen, 1971; Miller \& Nestel, 1973; Bastomsky, 1974; Kato \& Yoshida, 1981 ; Choe et al. 1984) also increase liver size, bile flow and serum cholesterol concentration. Similar results were also obtained in the present study.

We have already indicated that the incorporation of ${ }^{3} \mathrm{H}_{2} \mathrm{O}$ into hepatic cholesterol, and hepatic HMG-CoA reductase activity were significantly higher in rats given the PCBsupplemented diet than in control rats. Thus, we have suggested that the hyper- 
cholesterolaemia due to PCB-feeding is mediated by enhancement of cholesterol synthesis in the liver (Kato \& Yoshida 1980). To our knowledge, no one has studied the effects of PCBs on cholesterol catabolism, for example faecal or biliary excretion of steroids. Biliary excretion of bile acids was significantly decreased in rats given the PCB-supplemented diet and there was a concomitant decrease in their faecal excretion. As shown in other work (Tanaka et al. 1984), changes in faecal excretion of bile acids were similar to changes in biliary excretion of bile acids. These observations are similar to our own results in the present work. On the other hand, biliary output of cholesterol was significantly decreased in rats given the PCB-supplemented diet, whereas faecal output increased. These results agree with those of Uchida et al. (1978) who reported that changes in faecal output of steroids were not always parallel with changes in biliary excretion of steriods. Cholesterol is excreted by pathways additional to the bile duct, such as the intestinal wall. We suggest that the changes in biliary and faecal steriod excretion observed in the present study may reflect changes in cholesterol reabsorption and pathways for excretion. However, the specific mechanisms and physiological significance of these changes in cholesterol and bile acid metabolism are not clear at present.

In the guinea-pig receiving an inadequate dose of L-ascorbic acid there is an impairment in the conversion of cholesterol to bile acids resulting in hypercholesterolaemia (Ginter et al. 1971; Holloway \& Rivers, 1981). It is well-known that thyroid function profoundly affects cholesterol metabolism (Takeuchi et al. 1975; Abrams \& Grundy, 1981). For example, patients or rats with hyperthyroidism have low serum cholesterol concentrations, whereas those with hypothyroidism show high concentrations (Takeuchi et al. 1975; Abrams \& Grundy, 1981). These investigators suggested that the increase in serum cholesterol concentration due to ascorbic acid deficiency or hypothyroidism might be attributable mainly to the suppression of cholesterol catabolism. Furthermore, the hypocholesterolaemic effect of soya-bean protein compared with casein has been confirmed in the rat (Nagata et al. 1981; Tanaka et al. 1984). The hypocholesterolaemic effect of soyabean protein may be related to the increased excretion of faecal total steroids (Nagata et al. 1981). Thus, these findings indicate that the changes in the faecal excretion of total steroids may affect the serum cholesterol level. In the present study, the excretion of total steroids in the faeces is not significantly changed in rats given the PCB-supplemented diet. The present finding may indicate that the hypercholesterolaemia induced by dietary PCBs is not caused by the change in faecal total steroids excretion. Hence, in previous (Kato \& Yoshida, 1980; Nagaoka et al. 1986b) and present studies, we confirmed that the hypercholesterolaemia induced by dietary PCBs is mainly attributable to stimulation of liver cholesterol synthesis.

Hypercholesterolaemia induced by dietary PCBs would be a new model to elucidate not only the mechanisms of regulation of cholesterol metabolism, but also the regulation of lipoprotein metabolism.

This study was supported in part by a grant from Nissan Science Foundation and Elizabeth Arnold Fuji Foundation, Japan.

\section{REFERENCES}

Abaurre, R., Gordon, S. G., Mann, J. G. \& Kern, F. Jr (1969). Fasting bile salt pool size and composition after ileal resection. Gastroenterology 57, 679-688.

Abrams, J. J. \& Grundy, S. M. (1981). Cholesterol metabolism in hypothyroidism and hyperthyroidism in man. Journal of Lipid Research 22, 323-338.

Appleton, B. S., Shriver, C. N., Arnrich, L. \& Hathcock, J. N. (1981). Effects of 3-methylcholanthrene and DDT on cholesterol $7 \alpha$-hydroxylase in rats. Drug-Nutrient Interactions 1, 15-21. 
Bartlett, G. R. (1959). Phosphorous assay in column chromatogrphy. Joumal of Biological Chemistry 234, $466-468$

Bastomsky, C. H. (1974). Effects of polychlorinated biphenyl mixture (Aroclor 1254) and DDT on biliary thyroxine excretion in rats. Endocrinology 95, 1150-1155.

Bruusgaard, A., Sorensen, H., Gilhuus-Moe, C. C. \& Skalhegg, B. A. (1977). Bile acid determination with different preparations of $3 \alpha$-hydroxysteroid dehydrogenase. Clinica Chimica Acta 77, 387-395.

Choe, S. Y., Kim, H. M. \& Yang, K. H. (1984). Effects of butylated hydroxytoluene (BHT) on biliary excretion of xenobiotics and bile flow in rats. Drug and Chemical Toxicology 7, 149-165.

Folch, J., Lee, M. \& Sloane Stanley, G. H. (1957). A simple method for the isolation and purification of total lipid from animal tissues. Journal of Biological Chemistry 226, 497-509.

Frantz, I. D. Jr, Schneider, H. S. \& Hinkelman, B. T. (1954). Suppression of hepatic cholesterol synthesis in the rat by cholesterol feeding. Journal of Biological Chemistry 206, 465469.

Ginter, E., Cerven, J., Nemec, R. \& Mikus, L. (1971). Lowered cholesterol catabolism in guinea pigs with chronic ascorbic acid deficiency. American Journal of Clinical Nutrition 24, 1238-1245.

Harper, A. E. (1959). Amino acid balance and imbalance. I. Dietary level of protein and amino acid imbalance. Journal of Nutrition $68,405-418$.

Harry, D. S., Dini, M. \& McIntyre, N. (1973). Effect of cholesterol feeding and biliary obstruction on hepatic cholesterol biosynthesis in the rat. Biochimica et Biophysica Acta 296, 209-220.

Heaton, K. W., Heaton, S. T. \& Barry, R. E. (1971). An in vivo comparison of two bile salt binding agents, cholestyramine and lignin. Scandinavian Journal of Gastroenterology 6, 281-286.

Holloway, D. E. \& Rivers, J. M. (1981). Influence of chronic ascorbic acid deficiency and excessive ascorbic acid intake on bile acid metabolism and bile composition in the guinea pig. Journal of Nutrition 111, 412-424.

Ishikawa, T. T., McNeely, S., Steiner, P. M., Glueck, C. J., Milles, M., Gartside, P. S. \& McMillin, C. (1978). Effect of chlorinated hydrocarbons on plasma $\alpha$-lipoprotein cholesterol in rats. Metabolism 27, 89-96.

Karaboyas, G. C. \& Koritz, S. B. (1965). Identity of the site of action of 3',5'-adenosine monophosphate and adrenocorticotropic hormone in corticosteroidogenesis in rat adrenal and beef adrenal cortex slices. Biochemistry 4, 462-468.

Kato, N.\& Yoshida, A. (1980). Effect of dietary PCB on hepatic cholesterogenesis in rats. Nutrition Reports International 21, 107-112.

Kato, N. \& Yoshida, A. (1981). Effect of various dietary xenobiotics on serum total cholesterol and high density lipoprotein cholesterol in rats. Nutrition Reports International 23, 825-831.

Klassen, C. D. (1971). Studies on the increased biliary flow produced by phenobarbital in rats. Journal of Pharmacological and Experimental Therapeutics 176, 743-751.

Klassen, C. D. \& Watkins, J. B. (1984). Mechanisms of bile formation, hepatic uptake, and biliary excretion. Pharmacological Review 36, 1-67.

Malchøw-Møller, A., Arffmann, S., Larusso, N. F. \& Krag, E. (1982). Enzymatic determination of total $3 x$-hydroxy bile acids in faeces. Scandinavian Journal of Gastroenterology 17, 331-333.

Miettinen, T. A., Ahrens, E. H. Jr \& Grundy, S. M. (1965). Quantitative isolation and gas-liquid chromatographic analysis of total dietary and fecal neutral steroids. Journal of Lipid Research 6, 411-424.

Miller, N. E. \& Nestel, P. J. (1973). Altered bile acid metabolism during treatment with phenobarbitone. Clinical Science and Molecular Medicine 45, 257-262.

Nagaoka, S., Kato, M., Aoyama, Y. \& Yoshida, A. (1986a). Comparative studies on the hypercholesterolaemia induced by excess dietary tyrosine or polychlorinated biphenyls in rats. British Journal of Nutrition 56, 509-517.

Nagaoka, S., Masaki, H., Aoyama, Y. \& Yoshida, A. (1986b). Effects of excess dietary tyrosine or certain xenobiotics on the cholesterogenesis in rats. Journal of Nutrition 116, 726-732.

Nagata, Y., Tanaka, K. \& Sugano, M. (1981). Further studies on the hypocholesterolaemic effect of soya-bean protein in rats. British Journal of Nutrition 45, 233-241.

O'Brien, B. C. \& Reiser, R. (1982). Cholesterolemic response of rats to human-type diet ingredients. Journal of Nutrition 112, 1490-1497.

Okuyama, S., Kokubun, N., Higashidate, S., Uemura, D. \& Hirata, Y. (1979). A new analytical method of individual bile acids using high performance liquid chromatography and immobilized $3 x$-hydroxysteroid dehydrogenase in column form. Chemical Letters 1443-1446.

Pearson, S., Stern, S. \& McGavack, T. H. (1953). A rapid, accurate method for determination of total cholesterol in serum. Analytical Chemistry 25, 813-814.

Quazi, S., Yokogoshi, H. \& Yoshida, A. (1983). Effect of dietary fiber on hypercholesterolemia induced by dietary PCB or cholesterol in rats. Journal of Nutrition 113, 11091118.

Snedecor, G. W. \& Cochran, W. G. (1967). Statistical Methods (Japanese ed. : Iwanami Pub. Inc., Tokyo). Ames, Iowa: Iowa State University Press.

Takeuchi, N., Ito, M., Uchida, K. \& Yamamura, Y. (1975). Effect of modification of thyroid function on cholesterol $7 \alpha$-hydroxylation in rat liver. Biochemical Journal 148, 499-503.

Tanaka, K, Aso, B. \& Sugano, M. (1984). Biliary steroids excretion in rats fed soybean protein and casein or their amino acid mixtures. Journal of Nutrition $114,26-32$

Uchida, K., Nomura, Y., Kadowaki, M., Takase, H., Takano, K. \& Takeuchi, N. (1978). Age-related changes in cholesterol and bile acid metabolism in rats. Journal of Lipid Research 19, 544-552. 
Van Cantfort, J., Renson, J. \& Gielen, J. (1975). Rat-liver cholesterol $7 \alpha$-hydroxylase. European Journal of Biochemistry 55, 23-31.

Wahlefeld, A. W. (1974). Determination after enzymatic hydrolysis. In Methods of Enzymatic Analysis, vol. 4, pp. 1831-1935 [H. U. Bergmeyer, editor]. New York: Academic Press.

Waxman, D. J. (1986). Rat hepatic cholesterol $7 \alpha$-hydroxylase: biochemical properties and comparison to constitutive and xenobiotic-inducible cytochrome P-450 enzymes. Archives of Biochemistry and Biophysics 247, 335-345.

Yoshimura, H., Yamamoto, H. \& Kinoshita, H. (1974). Metabolic studies on polychlorinated biphenyls. V. Biliary excretion of 5-hydroxy-2,4,3',4'-tetrachlorobiphenyl, a major metabolite of $2,4,3^{\prime}, 4^{\prime}$-tetrachlorobiphenyl. Fukuoka Acta Medicine 65, 12-16.

Zilversmit, D. B. \& Davis, A. K. (1950). Microdetermination of plasma phospholipid by trichloroacetic acid precipitation. Journal of Laboratory and Clinical Medicine 35, 155-160 